\title{
Incidence of Mortality rates due to Tuberculosis in Association of South East Asian Nations and its relation to Current Health Expenditure Per Capita: A secondary Data Analysis
}

\author{
Laila Ayman Ahmed ${ }^{1}$, Jeevan K. Shetty ${ }^{2}$, V ishnumukkala Thirupathirao ${ }^{3}$, Venkatesh \\ R. Naik *4.
}

${ }^{1}$ Medical student, Perdana University-Royal College of Surgeon's in Ireland School of Medicine (PU-RCSI), Perdana University, Kuala Lumpur, Malaysia.

${ }^{2}$ Department of Biochemistry, Perdana University-Royal College of Surgeon's in Ireland School of Medicine (PU-RCSI), Perdana University, Kuala Lumpur, Malaysia.

${ }^{3}$ Department of Anatomy, Perdana University-Royal College of Surgeon's in Ireland School of Medicine (PU-RCSI), Perdana University, Kuala Lumpur, Malaysia.

${ }^{*}$ Department of Pathology, Perdana University-Royal College of Surgeon's in Ireland School of Medicine (PU-RCSI), Perdana University, Kuala Lumpur, Malaysia.

\section{ABSTRACT}

\begin{abstract}
Introduction: Tuberculosis is a devastating health condition with a high incidence in the ASEAN population. This study analyses mortality trends due to TB among the Association of South East Asian Nations (ASEAN) and also investigates the relationship between mortality and Current health expenditure (CHE) per capita

Methods: This study is a secondary data analysis on mortality rates and CHE per capita from the year 2002 to 2017. The data was obtained from global health observatory data repository databases and World Bank Organization respectively. They were analysed using SPSS trial version 23.
\end{abstract}

Results: This study showed an overall reduction in mortality rates among the ASEAN countries except Brunei Darussalam which showed an increase. This study also showed an indirect intermediate correlation between mortality rates and CHE per capita.

Discussion: Among the ASEAN, Singapore, which follows the TB control program suggested by WHO, achieved 2/5 TB control performance indicators. Its healthcare spending has almost doubled since 2010. Since implementation of directly observed treatment, short-course in Thailand in 2001, Thailand has succeeded achieving the detection target. Brunei Darussalam witnessed an increase in mortality rate. The rise in the number of people with chronic Non -communicable Diseases, especially diabetes mellitus, is posing a major challenge to Brunei's TB control efforts. Myanmar has a heavy TB burden, it seeks to cut TB incidence in half by 2025.

Key words: Tuberculosis, ASEAN, Secondary data analysis, Mortality, Current health expenditure per capita.

Address for correspondence: Assoc. Prof. Dr. Venkatesh R.Naik, Lead and Associate Professor in Pathology, PU-RCSI School of Medicine- Perdana University, Suite 9, 9th Floor, Wisma Chase Perdana, Changkat Semantan Damansara Heights, 50490 Kuala Lumpur, Malaysia.

Ph No: +60386579534 E-Mail: venkatesh@perdanauniversity.edu.my

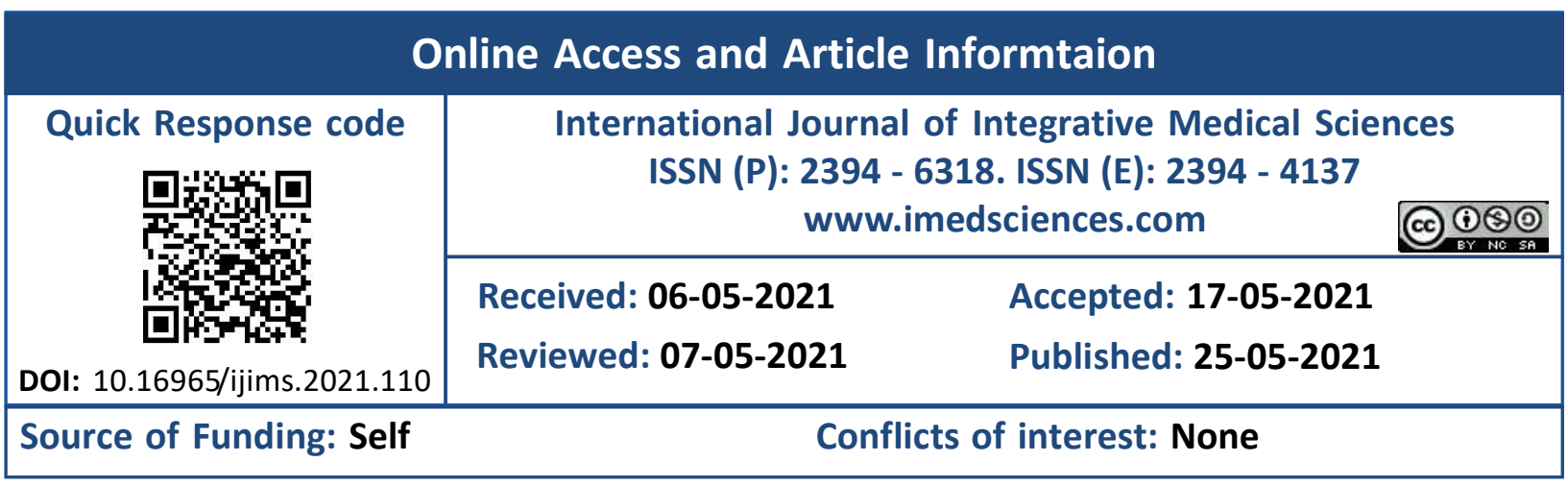

INTRODUCTION

Tuberculosis (TB) is an infectious disease that is caused by bacteria called Mycobacterium tuberculosis [1]. Tuberculosis is caused by the 
inhalation of air droplets when an infected person coughs or sneezes [1].

TB can be categorised into pulmonary and extra pulmonary infections [2]. Typically TB affects the lungs, but it can affect other organs such as kidneys, liver, gastrointestinal tract, heart, brain, and spine as well [2]. General symptoms of TB infection include fever, fatigue, night sweats, and weight loss [3]. Ordinarily, pulmonary TB infection presents with cough, hemoptysis, and chest pain [3]. Extra pulmonary TB infections presents with symptoms depending on the troubled organ [3]. TB is also categorised as active TB or latent TB [2]. Active TB is also called TB disease which is contagious and causes symptoms that vary according to the site of infection whether it is pulmonary or extra pulmonary [2]. Latent TB infection means getting positive TB skin and blood test with absence of symptoms and it is not contagious. ${ }^{2}$ However, $5 \%-10 \%$ of the latent TB cases develop into active TB mainly due to immunocompromising conditions [2]. TB is treated by a course of 4 antibiotics for 6 months [1].

TB was the first infectious diseases declared as a global emergency by the World Health Organization [4]. The enforcement of directly observed therapy short course (DOTS) has been an advancement in the control of TB infection [4]. DOTS has become essential for TB treatment to ensure compliance to the medication, avoid resistance allowing the patient complete the treatment in the least period of time. ${ }^{3}$ Multidrug resistant TB is resistant to isoniazid and rifampin the most commonly used antibiotics in the first line regimen [5]. Drug resistance developed due to improper administration of TB medication or poor compliance to antibiotics which [5]. Multidrug resistant TB imposes a global threat as it impedes health and economic development as a single multi drug resistant TB case can cost thousands of times more than a drug susceptible TB case [5]. According to the World Health Organization around one-fourth of the world's population is infected by TB but only $5 \%-15 \%$ of these people develop active TB [1]. However, in 2019, an estimated 10 million people fell sick with TB globally with the highest cases of around $44 \%$ of cases and $50 \%$ of mortalities caused by TB are occurring in South-East Asia [6].

Association of South-East Asian Nations (ASEAN) is an international organisation made up of 10 member countries in the South-East Asian region; Malaysia, Brunei, the Philippines, Indonesia, Myanmar, Laos, Singapore, Cambodia, Thailand, and Vietnam [7]. ASEAN aims to enhance cultural and economic exchange amongst member countries, to preserve stability and peace in South East Asia [7]. Most common diseases causing mortality in South-East Asia comprises of communicable diseases (HIV, TB and malaria) and non- communicable diseases (cardiovascular diseases, chronic respiratory diseases, cancer and diabetes) $[8,9]$.

Current health expenditure (CHE) per capita is defined as health care spending on health care goods or services in a year per person in a country. ${ }^{10}$ It helps to understand health spending in relation to population size making international comparisons easier [11].

TB is the world's second infectious disease killer competing with HIV. Despite the declining trend in TB incidence and mortality rates, eradication of TB at a global level is impossible. So this study analyses the mortality trends in ASEAN population due to pulmonary tuberculosis and the impact of CHE per capita on mortality rates. This means it focuses on the challenges and resources available to assist in establishing an intervention plan to reduce transmission and resistance and thus mortality.

\section{MATERIALS AND METHODS}

Study Design: This study is a secondary data analysis on mortality rates due to pulmonary TB and to compare it with CHE per capita.

Study subjects: Data on mortality rates due to pulmonary TB in ASEAN countries were collected from the "The Global Health Observatory Data Repository" (GHODR) database.

GHODR is a publicly accessible database for health statistics of the World Health Organization for 194 Countries. It provides statistical data on over 1,000 health factors, 
including death rates, child nutrition, maternal health, environmental health, HIV/AIDS, equity etc.

Data on ASEAN countries' Current health expenditure (CHE) was collected from World Bank organization database.

Inclusion and exclusion criteria: The countries included in the data sets for mortality rates and CHE per capita were the ASEAN countries (Malaysia, Brunei, the Philippines, Indonesia, Myanmar, Laos, Singapore, Cambodia, Thailand, and Vietnam) for the years 2002 till 2017.

Data was excluded if the countries were out to of the ASEAN region or if the years were before 2002 or after 2017.

Research methods: The Global Health Observatory Data Repository GHODR database was used to get the data of the mortality rates per 100000 population due to TB among the ASEAN population. Data was filtered by country and years from 2012 to 2017. The filtered data was then downloaded as a CSV file.

Statistical methods: The data regarding mortality rates and $\mathrm{CHE}$ per capita were exported to SPSS trial version 1.0.0.1508 software. The correlation between $\mathrm{CHE}$ per capita and mortality rates were tested using Pearson correlation. Means of CHE per capita and mortality rates were compared using independent samples $T$ test, the significance threshold ( $P$ value) was set at .05 .

Ethical approval: All the data is available on GHO and World Bank site is open access to the public. The ethical clearance of this study was approved by the university ethical clearance board.

\section{RESULTS}

Mortality rates trend in ASEAN population: From 2002 to 2017, there was an overall a reduction in mortality rate per 100000 due to TB among the ASEAN population except for Brunei Darussalam which witnessed an increase in mortality rates by $35.5 \%$ from 3.1 deaths per 100000 to 4.2 per 100000 (Graph 1 $\mathrm{a}, \mathrm{b})$. Myanmar and Singapore had the highest reduction in mortality rate per 100000 . It reduced by $70.8 \%$. Whereas, Thailand had the least reduction in mortality rate per 100000 , reducing by $30 \%$ from 20 deaths per 100000 to 14 per 100000. Cambodia, Lao People's Democratic Republic, and Viet Nam had successfully experienced a decrease in mortality rates per 100000 by more than $50 \%, 52.5 \%$, $66.4 \%$, and $62.5 \%$ respectively. Indonesia, $\mathrm{Ma}-$ laysia and Philippines had a reduction in mortality rate per 100000 by more than $30 \%, 33.3 \%$, $39.1 \%$ and $42.6 \%$ respectively.

Mortality trends among ASEAN countries 20022017 (Graph 1a, 1b)

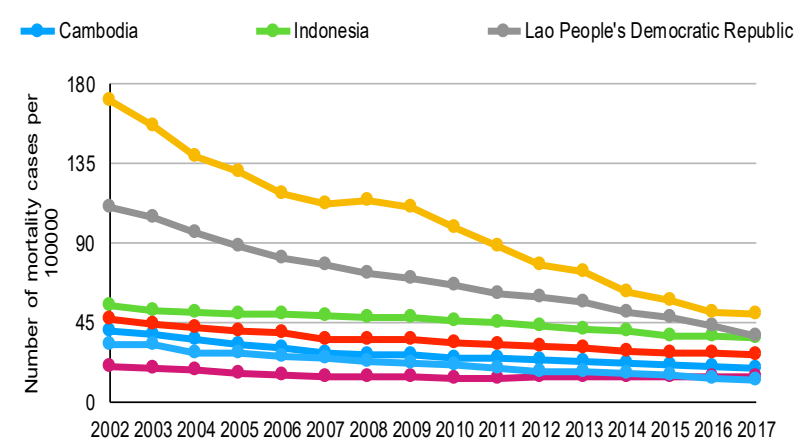

Year

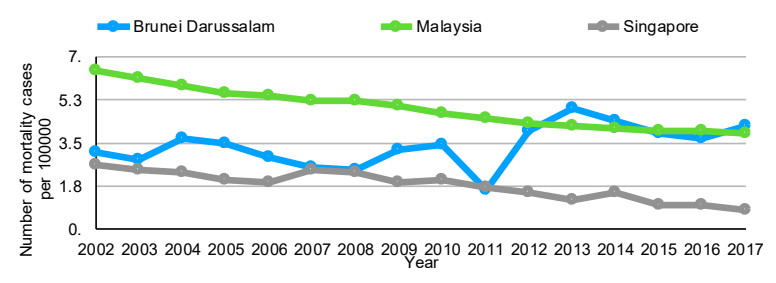

Association between mean CHE per capita and mortality due to TB in ASEAN population: The $r$ value corresponding to the correlation between mean mortality rates per 100000 from 2002 to 2017 and CHE per capita is equal to -0.543 which means there is indirect intermediate correlation.

Among the ASEAN population, Singapore had the highest mean CHE per capita from 2002 to 2017 of 1550 USD which might explain the reduction in mortality rate per 100000 by $70.8 \%$. Myanmar also had the same reduction rate mortality rate per 100000 although mean health care expenditure from 2002 to 2017 was 27 USD which is the lowest mean CHE per capita. Brunei Darussalam experienced an increase in mortality rate although it had the second highest mean CHE per capita from 2002 to 2017 which was 716 USD, this might indicate role of other factors contributing to mortality rates due to TB. Lao PDR had the second highest reduction in mortality rates after Myanmar and Singapore from 2002 to 
2017 by $66.4 \%$ not withstanding that mean CHE per capita from 2002 to 2017 was only 33 USD.

Association between mean CHE per capita and mortality due to TB in ASEAN population 20022017 (Graph2)

$$
\text { - Mean Mortality per } 100000
$$

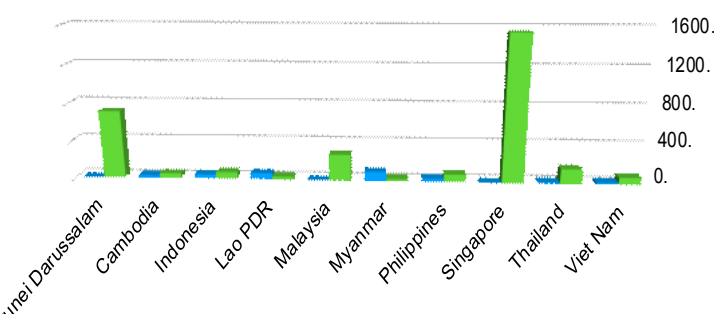

Table 1: Showing the Mean mortality cases and CHE.

\begin{tabular}{lcc}
\hline & $\begin{array}{c}\text { Group 1 } \\
\text { (<100USD CHE per } \\
\text { capita) }\end{array}$ & $\begin{array}{c}\text { Group 2 } \\
\text { (>100USD CHE per } \\
\text { capita) }\end{array}$ \\
\hline $\begin{array}{c}\text { Mean TB mortality cases / } \\
100000 \text { population }\end{array}$ & $50.02^{*}$ & 6.27 \\
Mean CHE per capita in USD & $57.83^{* *}$ & 677 \\
\hline * $p<0.05$ in comparison to mean CHE per capita in USD \\
$* * p<0.05$ in comparison to mean TB mortality cases / \\
100000 population
\end{tabular}

As almost half of the ASEAN countries had a CHE per capita of less than 100 USD and the other half had a CHE per capita of more than 100 USD per capita this will allow us to compare the impact of $\mathrm{CHE}$ per capita on mortality rates. A figure of 100USD was taken for convenience and this figure is close to the recommended amount which is 86USD. ASEAN countries were divided into two groups. Group 1 are the ASEAN countries with mean CHE per capita less than 100 USD; Cambodia, Indonesia, Lao PDR, Myanmar, Philippines, and Viet Nam. Group 2 are the ASEAN countries with a mean CHE per capita of more than 100 USD; Brunei Darussalam, Malaysia, Singapore, and Thailand. Group 1 countries had higher mean mortality rates per 100000 population compared to group 2. $\mathrm{P}$ value of mean $\mathrm{CHE}$ per capita in comparison to mean TB mortality cases / 100000 population is $<0.05$. A significant relationship was found between mean mortality cases per 100000 population and mean CHE per capita $(p<.05)$. This suggests that this relationship is not likely to be due to chance. Countries with mean CHE per capita less than 100 USD are likely to experience higher mortality rates due to TB and vice versa.

\section{DISCUSSION}

The aim of this study is to evaluate the trend of mortality rates due to TB from 2002 to 2107 among the ASEAN population and the influence of CHE per capita on the mortality rates.

There was an overall reduction in mortality rates per 100000 population due to TB among the ASEAN population excluding Brunei Darussalam.

Singapore had the highest overall reduction in mortality rate by $70.8 \%$ from 2002 to 2017 . However, the reduction trend was interrupted in 2007 showing a spike from 1.9 mortality cases per 100000 population in 2006 to 2.4 mortality cases per 100000 population in 2007. According to a retrospective cohort study conducted in Singapore and published in 2009, risk factors that are potentially associated with mortality due to TB are; patient of older age, Malay ethnicity, male sex and being in a long term care facility. Comorbidity and weakened immune system among old age group may account for increased risk of death due to TB [12]. Singapore is following the TB control program which is suggested by the World Health Organization in which it only achieved two out of five of TB control performance indicators [12]. It achieved in reducing mortality rate by half from 1990 to 2015 and increasing of detection rate of TB under DOTS by $70 \%$ by at least 2005 [12].

Among the ASEAN countries, mean CHE per capita from 2002 to 2017 was highest for Singapore which was 1550 USD per capita. National healthcare spending has almost doubled since 2010 [13]. Subsidies have also increased by a 2.4-fold spike in government health spending [13].

Thailand had the lowest overall reduction in mortality rates of $30 \%$ from 2002 to 2017 . However, the reduction trend was interrupted in 2012 showing a spike of 13 mortalities per 100000 population in 2011 to 14 mortalities per 100000 population in 2012 and remain consistent throughout till 2017. Since the implementation of DOTS in Thailand in 2001, 
Thailand has succeeded in achieving the international TB cases detection target but failed to achieve the TB treatment success target which is $85 \%$ [14].

Brunei Darussalam witnessed a reduction in mortality rate by $48.4 \%$ in 2011 followed by $61.9 \%$ increase in mortality rate in 2017 , showing an overall increase in mortality rate by $35.5 \%$ in 2017 . The rise in the number of people with chronic non communicable diseases, especially diabetes mellitus, is posing a major challenge to Brunei's TB control efforts [15]. The ongoing TB occurrence in Brunei is attributed to the increase in Non - communicable diseases, as well as an ageing population that is more prone to TB reactivation and smoking [15]. As a result, NCD prevention and control are critical in the fight against tuberculosis in Brunei Darussalam [15]. Brunei Darussalam had the second highest mean CHE per capita which was 716 USD per capita yet it faced an in increase in mean mortality per 100000.

Myanmar presented a steady reduction throughout the years from 2002 to 2017 with overall reduction rate of mortality cases per 100000 population by $70.8 \%$, same as Singapore. Myanmar is one of the 30 countries with a heavy TB burden, with a prevalence rate that is double the regional average and three times the global average [16]. Its National Strategic Plan (NSP) for TB, 2021-2025, seeks to cut TB incidence in half by 2025 and end the epidemic by 2035 [17]. This NSP distinguishes and categorises the tactics to be applied into five strategic directions [17]. Myanmar had the lowest mean CHE per capita which was 27 USD. Myanmar's health-care sector is chronically underfunded [18].

\section{CONCLUSION}

Tuberculosis is a devastating health condition which impacts the ASEAN population. The findings of this study can be used by public health authorities to devise a strategy for controlling the infection. Health care systems need to act towards implementing a stronger TB control plan. ASEAN countries can follow Myanmar NSP as Myanmar had succeeded inreducing mortality rates by $70.8 \%$ while having the lowest CHE per capita in the ASEAN region.

Limitations: The limitation of this study is the use of English language data only ranging from 2002 to 2017

\section{REFERENCES}

[1]. Tuberculosis [Internet]. Who.int. [cited 2021 May 3]. Available from: https://www.who.int/healthtopics/tuberculosis

[2]. Santos-Longhurst A. Types of Tuberculosis [Internet]. Healthline.com. 2019 [cited 2021 May 3]. Available from: https://www.healthline.com/health/ types-of-tuberculosis

[3]. Cdc.gov. [cited 2021 May 3]. Available from: https:/ /www.cdc.gov/tb/publications/factsheets/ general.htm $\hat{A}$

[4]. Zaman K. Tuberculosis: a global health problem. J Health Popul Nutr. 2010;28(2):111-3.

[5]. Tballiance.org. [cited 2021 May 3]. Available from: https://www.tballiance.org/why-new-tb-drugs/ antimicrobial-resistancê̂A

[6]. Tuberculosis [Internet]. Who.int. [cited 2021 May 3]. Available from: https://www.who.int/newsroom/fact-sheets/detail/tuberculosis

[7]. Moon C-I. ASEAN. In: Encyclopedia Britannica. 2020.

[8]. Gupta I, Guin P. Communicable diseases in the South-East Asia Region of the World Health Organization: towards a more effective response. Bull World Health Organ. 2010;88(3):199-205.

[9]. Who.int. [cited 2021 May 3]. Available from: https://www.who.int/nmh/ncd-tools/who-regions-south-east-asia/en/Â

[10]. Current health expenditure per capita (current US\$) [Internet]. Indexmundi.com. [cited 2021 May 3]. Available from: https://www.indexmundi.com/ facts/indicators/SH.XPD.CHEX.PC.CD

[11]. Current health expenditure (CHE) as percentage of gross domestic product (GDP) (\%) [Internet]. Who.int. [cited 2021 May 3]. Available from: https:/ /www.who.int/data/gho/data/indicators/indicator-details/GHO/current-health-expenditure-(che)as-percentage-of-gross-domestic-product-(gdp)-(-)

[12]. Gilliam E, Hoffman JD, Yeh G. Urogenital and pelvic complications in the Ehlers-Danlos syndromes and associated hypermobility spectrum disorders: A scoping review. Clin Genet. 2020;97(1):168-78.

[13]. hermes. Parliament: Rate of growth in healthcare spending unsustainable, says Gan Kim Yong [Internet]. Straitstimes.com. 2019 [cited 2021 May 3]. Available from: https://www.straitstimes.com/ singapore/health/rate-of-growth-in-healthcarespending-unsustainable-gan

[14]. Jittimanee S, Vorasingha J, Mad-asin W, Nateniyom S, Rienthong S, Varma JK. Tuberculosis in Thailand: epidemiology and program performance, 20012005. Int J Infect Dis. 2009;13(4):436-42. 
[15]. Newly diagnosed tuberculosis cases in Brunei up 14.8 pct in 2016 - Xinhua [Internet]. Xinhuanet.com. 2017 [cited 2021 May 3]. Available from: http://www.xinhuanet.com//english/ 2017-03/24/c_136155826.htm

[16]. endTB in Myanmar [Internet]. Endtb.org. [cited 2021 May 3]. Available from: http:// www.endtb.org/myanmar

[17]. Burma Tuberculosis Roadmap overview, fiscal year 2021 [Internet]. Usaid.gov. [cited 2021 May 3]. Available from: https://www.usaid.gov/globalhealth/health-areas/tuberculosis/resources/newsand-updates/global-accelerator-end-tb/tbroadmaps/burma
[18]. Knodel J, Teerawichitchainan B. Aging in Myanmar. Gerontologist. 2017; gnw211.

[19]. WHO | Spending targets for health: no magic number. 2019 [cited 2021 May 3]; Available from: https://www.who.int/health_financing/documents/no-magic-number/en/

How to cite this article: Laila Ayman Ahmed, Jeevan Shetty, Vishnumukkala Thirupathirao, Venkatesh R. Naik. Incidence of Mortality rates due to Tuberculosis in Association of South East Asian Nations and its relation to Current Health Expenditure Per Capita: A secondary Data Analysis. Int J Intg Med Sci 2021;8(3):993998. DOI: $10.16965 / \mathrm{ijims} .2021 .110$ 